\title{
Combination of endogenous neural stem cell mobilization and lithium chloride treatment for hydrocephalus following intraventricular hemorrhage
}

\author{
QIANG YUAN $^{1}$, XING-YAO BU $^{1}$, ZHAO-YUE YAN $^{1}$, XIAN-ZHI LIU $^{2}$, \\ ZHEN-YU WEI ${ }^{1}$, CHUN-XIAO MA ${ }^{1}$ and MING-QI QU ${ }^{1}$ \\ ${ }^{1}$ Department of Neurosurgery, People's Hospital of Zhengzhou University; ${ }^{2}$ Department of Neurosurgery, \\ The First Affiliated Hospital of Zhengzhou University, Zhengzhou, Henan 450003, P.R. China
}

Received June 25, 2015; Accepted August 16, 2016

DOI: 10.3892/etm.2016.3778

\begin{abstract}
As there are multiple factors causing hydrocephalus subsequent to intraventricular hemorrhage (IVH), it is difficult to achieve the best treatment effect using a single drug alone. In the present study, the protective effect of combination treatment with granulocyte-colony stimulating factor (G-CSF) and lithium chloride against hydrocephalus after IVH was investigated. A total of 130 adult male Sprague-Dawley rats were divided into five groups, including the IVH control, G-CSF treatment, lithium chloride treatment, combination treatment and sham surgery groups. An IVH rat model was established in order to examine the effect of combination treatment on hydrocephalus incidence. A TUNEL assay was performed to detect neuronal apoptosis in the five groups. In addition, the protein expression levels of B-cell lymphoma 2 (Bcl-2) and Bcl-2-associated X protein (Bax) were detected by western blot analysis. The differentiation of nerve cells in the brain tissue obtained from the five rat groups was also determined with double immunofluorescence staining. The results demonstrated that administration of G-CSF or lithium chloride alone was able to only partly relieve the incidence of hydrocephalus after IVH. By contrast, combination treatment with G-CSF and lithium chloride significantly attenuated the development of hydrocephalus following IVH. TUNEL assay showed that neuronal apoptosis was significantly reduced by the combination treatment with G-CSF and lithium chloride. Furthermore, the expression of Bcl-2 was upregulated, whereas Bax expression was downregulated in the combination treatment group. The results also detected the highest expression of BrdU/GFAP, BrdU/NeuN and BrdU/PSA-NCAM in the
\end{abstract}

Correspondence to: Dr Xing-Yao Bu, Department of Neurosurgery, People's Hospital of Zhengzhou University, 7 Weiwu Road, Zhengzhou, Henan 450003, P.R. China

E-mail: buxingyao1@163.com

Key words: combination treatment, granulocyte-colony stimulating factor, endogenous neural stem cells, lithium chloride, hydrocephalus combination treatment group. In conclusion, the combination of endogenous neural stem cell mobilization (using G-CSF) and lithium chloride treatment resulted in highly reduced incidence of hydrocephalus after IVH by inhibiting neuronal apoptosis.

\section{Introduction}

Hydrocephalus, which is characterized by cerebrospinal fluid circulation disorder, pathological expansion of the ventricle and/or subarachnoid space, and cerebral shrinkage, is a common complication occurring after intraventricular hemorrhage (IVH) $(1,2)$. Hydrocephalus leads to decreased cognitive function and neurological damage, seriously affecting the prognosis of patients (3). Previous studies have suggested that the key causes of hydrocephalus subsequent to IVH may be the apoptosis or death of stem cells as a result of the presence of various inflammatory and pro-apoptotic factors in the micro-environment, which are released after IVH $(2,4)$. However, the underlying mechanism of hydrocephalus occurring after IVH is not fully understood.

Although surgery has been used as the main treatment for hydrocephalus, it commonly leads to certain complications and has a poor success rate. Currently, studies focus on the reconstruction of the body's resources in order to repair neurologic function $(5,6)$. In addition, the mobilization of endogenous neural stem cells has been investigated as an alternative and less invasive approach for brain injury (7). Granulocyte-colony stimulating factor (G-CSF) is a well-established stem-cell mobilizer for endogenous neural stem cell transplantation, in which CD34 is used as a marker of hemopoietic stem cells (8). G-CSF stimulates the proliferation, survival and maturation of cells committed to the neutrophilic granulocyte lineage through binding to the specific G-CSF receptor (9). In brain injury, G-CSF has been shown to be upregulated and to present strong nerve regeneration ability in vivo and in vitro (10). Lithium chloride is the most commonly used drug for the treatment of manic depressive illness and is reported to be a neuroprotective agent (11), exerting this effect through the inhibition of cell apoptosis and inflammation $(12,13)$. Wnt pathway serves a key role in the proliferation and differentiation of neural stem cells (14). Lithium chloride may regulate the Wnt signaling 
pathway in order to reduce the apoptosis of nerve cells and promote the differentiation of neural stem cells $(15,16)$.

As there are multiple factors causing hydrocephalus subsequent to IVH, it is difficult to achieve the best treatment effect using a single drug alone. Therefore, an increasing number of studies have researched the effect of treatment using a combination of drugs on hemorrhage $(17,18)$. Vose et al reported that treatment with $\mathrm{TH}$ accelerated the proliferation and maturation of oligodendrocytes and restored neurological function in pups with IVH (19). In the present study, the protective effect of the combination of endogenous neural stem cell mobilization and lithium chloride treatment on hydrocephalus following IVH was investigated. The study examined the inflammation, apoptosis and neuranagenesis in the brain following the combination treatment. The current findings provide evidence on the effect of this noninvasive treatment for hydrocephalus subsequent to IVH.

\section{Materials and methods}

Animal groups. Animal use protocols were approved by People's Hospital of Zhengzhou University Committee on the Use and Care of Animals (Zhengzhou, China). Animals were provided by Henan Experimental Animal Center of Zhengzhou. A total of 130 newborn Sprague-Dawley (SD) rats at postnatal day 4 (weight, 5-10 g) were used in the present study and were reared with their dams. The dams and the newborn rats were housed at $18-25^{\circ} \mathrm{C}$ in an atmosphere of $50-70 \%$ relative humidity, with a $12-\mathrm{h}$ light/dark cycle. Rats were randomly divided into five groups: IVH control group ( $n=30$; Group 1); G-CSF treatment group ( $=30$; Group 2); lithium chloride treatment group ( $\mathrm{n}=30$; Group 3); combination treatment group ( $\mathrm{n}=30$; Group 4); and sham surgery group ( $n=10$; Group 5). Rats in Group 1 received hypodermic injection of saline on days $2,4,6$, and 8 and intraperitoneal injection after 2 days of IVH. Rats in Group 2 received a hypodermic injection of $50 \mu \mathrm{g} / \mathrm{kg} /$ day G-CSF (Sigma-Aldrich, St. Louis, MO, USA) on days 2, 4, 6 and 8, and intraperitoneal injection of saline with equal amounts with lithium chloride after 2 days of IVH. Rats in Group 3 were given a hypodermic injection of saline with equal amounts with G-CSF and intraperitoneal injection of $3 \mathrm{mmol} / \mathrm{kg} /$ day lithium chloride after 2 days of IVH. Group 4 rats received combination treatment with a hypodermic injection of $50 \mu \mathrm{g} / \mathrm{kg} /$ day G-CSF on days $2,4,6$ and 8 , as well as intraperitoneal injection of $3 \mathrm{mmol} / \mathrm{kg} / \mathrm{day}$ lithium chloride after 2 days of IVH. Rats in Group 5 were subjected to sham surgery and received no treatment.

Animal model. The IVH rat model was established as previously described by Ahn et al (20) and Lodhia et al (21). Briefly, SD rats were anesthetized using 1.5-2\% isoflurane (Sigma-Aldrich) in an oxygen-enriched atmosphere $(20,21)$. A total of $100 \mu \mathrm{l}$ fresh whole blood from the pregnant rats was slowly infused into the right ventricles over $5 \mathrm{~min}$ at a rate of $10 \mu \mathrm{l} / \mathrm{min}, 1.7 \mathrm{~mm}$ lateral to the sagittal suture, $3.8 \mathrm{~mm}$ posterior to the coronal suture and at a depth of $3.5 \mathrm{~mm}$. After $10 \mathrm{~min}$, equal amount of fresh maternal whole blood was infused into the left ventricles. For rats in Group 1, the same amount of saline was infused into the right and left ventricles rather than fresh maternal whole blood, according to the aforementioned procedure. The animals were then allowed to recover from anesthesia. Rats received intraperitoneal injection of $10 \mathrm{mg} / \mathrm{kg}$ /day bromodeoxyuridine (BrdU; Sigma-Aldrich; one day after surgery) to mark neural stem cells under proliferation. Rats in group 5 underwent a sham operation without blood injection.

Tissue collection. Rats in each group were divided into the day 11, 18 and 32 time points. At each time point, rats were fixed on the experimental platform under deep anesthesia with $400 \mathrm{mg} / \mathrm{kg}$ chloral hydrate (Sigma-Aldrich). Next, the hair on the chest and abdomen was removed and the heart was exposed. The rats were decapitated and the brain was placed in paraformaldehyde solution. Brain tissue was collected in the periventricular cerebral mass, corpus callosum region, subventricular zone (SVZ) and hippocampal dentate gyrus and cut into sections of $2 \mathrm{~mm}$. Subsequently, the obtained tissue was moved into sucrose solution treated with diethyl pyrocarbonate (Sigma-Aldrich) for $48 \mathrm{~h}$. The tissue was then sliced into $5 \mu \mathrm{m}$ using a freezing microtome and loaded onto glass slides. The samples were wrapped up with aluminized paper and stored at $-70^{\circ} \mathrm{C}$.

Cell apoptosis assay. Cell death of nerve cells in the periventricular cerebral mass, corpus callosum region, SVZ and hippocampal dentate gyrus brain tissue was assessed using the immunofluorescent terminal deoxynucleotidyl transferase-mediated deoxyuridine triphosphate nick-end labeling (TUNEL) in the ApopTag Fluorescein In Situ Apoptosis Detection kit (cat. no. S7110; Chemicon; Merck Millipore, Temecula, CA, USA) according to the manufacturer's instructions. The nucleus presenting yellow or light yellow bulk or appearing granular under the light microscope was considered as TUNEL-positive. A blinded evaluator counted the number of TUNEL-positive nuclei in the brain tissue samples from the periventricular cerebral mass, corpus callosum region, SVZ and hippocampal dentate gyrus. A total of 10 random non-overlapping fields of view from each brain were counted.

Western blot analysis. In order to perform immunoblotting analysis, brain tissue obtained from rats in each group was lysed by radioimmunoprecipitation assay lysis buffer (Beyotime Institute of Biotechnology, Inc., Shanghai, China) and homogenates were centrifuged at 9,200 x $g$ for $15 \mathrm{~min}$ at $4^{\circ} \mathrm{C}$. Then the supernatant was collected and used for protein concentration determination using a Bradford protein assay kit (Beyotime Institute of Biotechnology). A total of $15 \mathrm{mg}$ protein was loaded onto each lane of an $8 \%$ sodium dodecyl sulfate-polyacrylamide gel containing $4 \mathrm{~mol} / \mathrm{l}$ urea, and electrophoresis was performed under standard conditions. Next, the protein sample was electrophoretically transferred to Immobilon-P polyvinylidene difluoride membranes (Merck Millipore) by semidry blotting. Subsequent to blocking in $3 \%$ nonfat dry milk in Tris-buffered saline/Tween 20 (TBST;

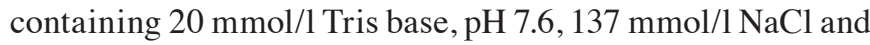
$0.05 \%$ Tween 20 ) for $1 \mathrm{~h}$ at room temperature, the membranes were incubated with antibodies against rabbit polyclonal anti-B cell lymphoma-2(Bcl-2; 1:500; cat.no.ab59348; Abcam, Cambridge, UK), rabbit polyclonal anti-Bcl-2-associated X protein (Bax; 1:500; cat. no. ab69643; Abcam), or rabbit 

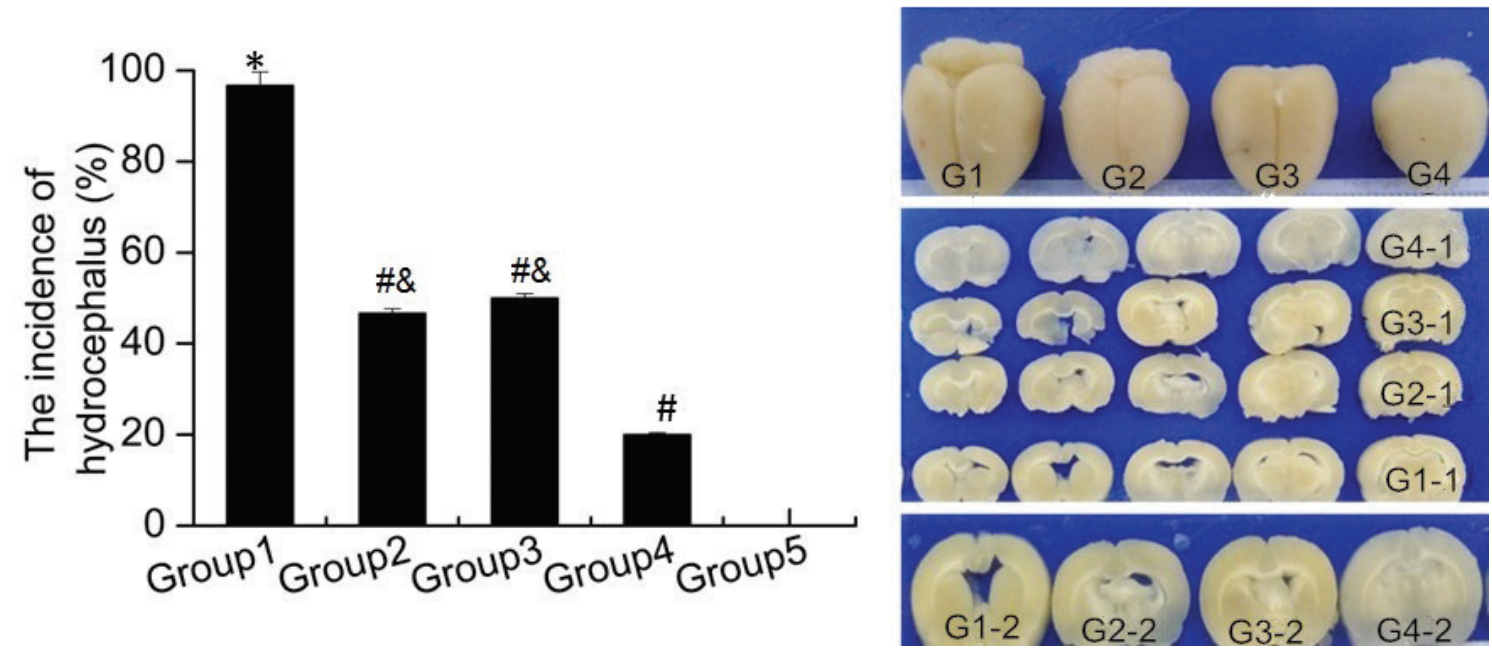

Figure 1. Effect of combination treatment with granulocyte-colony stimulating factor and lithium chloride on hydrocephalus. (A) Incidence of hydrocephalus after intraventricular hemorrhage in the various study groups. The results are presented as the mean \pm standard deviation. ${ }^{*} \mathrm{P}<0.05$ vs. Group 5 ; ${ }^{*} \mathrm{P}<0.05$ vs. Group 1; ${ }^{\mathrm{P}}<0.05$ vs. Group 4. (B) Photographs of brain tissue of rats in the various study groups. G1, Group 1; G2, Group 2; G3, Group 3; G4, Group 4; G1-1-G4-1, serial section of G1-G4; G1-2-G4-2, the enlarged and typical images of G1-G4.

polyclonal anti-GAPDH (1:2,500; cat. no. ab9485; Abcam) overnight at $4^{\circ} \mathrm{C}$. The membranes were washed in TBST and then incubated for $1 \mathrm{~h}$ at room temperature with horseradish peroxidase-conjugated goat anti-rabbit IgG H\&L (1:10,000; cat. no. ab97051; Abcam). Immunoreactive bands were visualized in the linear range with enhanced chemoluminescence (Sigma-Aldrich). The scanned images were semi-quantitated using Quantity One software (Bio-Rad Laboratories, Inc., Hercules, CA, USA). The relative integrated density values were calculated using FluorChem 2.0 software (Alpha Innotech Corporation, San Leandro, CA, USA) and normalized with GAPDH.

Double immunofluorescence. For the double immunofluorescence detection of BrdU along with glial fibrillary acidic protein (GFAP), neuronal nuclei (NeuN) or polysialylated-neural cell adhesion molecule (PSA-NCAM). Brain sections were washed in phosphate-buffered saline (PBS) and pre-incubated for 60 min in blocking buffer (5\% normal donkey serum in PBS with $0.3 \%$ Triton X-100; both obtained from Sigma-Aldrich). Next, the brain tissue sections were incubated with the sheep polyclonal anti-BrdU antibody (1:1,000; cat. no. M20105S; Biodesign Inc., Saco, ME, USA), in addition to the goat polyclonal anti-GFAP (1:400; cat. no. sc-9065; Santa Cruz Biotechnology Inc., Santa Cruz, CA, USA), the mouse monoclonal anti-NeuN (1:500; cat. no. MAB377; Chemicon; Merck Millipore) or the mouse monoclonal anti-PSA-NCAM antibody (1:1,000; cat. no. MAB5324; Chemicon; Merck Millipore) for $12 \mathrm{~h}$ at $4^{\circ} \mathrm{C}$. Subsequently, the sections were incubated with the fluorescein isothiocyanate (FITC)-labeled donkey anti-sheep IgG (1:500; Molecular Probes; Thermo Fisher Scientific Inc., Eugene, OR, USA) and rhodamine-labeled horse anti-mouse IgG (1:500; Chemicon; Merck Millipore) antibodies for $1 \mathrm{~h}$. The sections were then rinsed in the dark, mounted on polylysine-coated slides and coverslipped using anti-fadent solution (Biomart, Shanghai, China). The tissue sections were viewed and photographed using epifluorescence on an Axiophot epifluorescence microscope with appropriate filter sets for fluorescein (excitation, 450-490 nm; emission, 514-565 nm) and Texas red (excitation, 530-585 nm; emission, >615 nm).

Statistics. Data are presented in the present study as the mean \pm standard deviation. Statistical differences among groups were determined using a Student's t-test. Analysis of variance with a Newman-Keuls post-hoc test was used for multiple comparisons. SPSS version 13.0 software (SPSS, Inc., Chicago, IL, USA) was used to analyze the data. A value of $\mathrm{P}<0.05$ was considered to indicate statistically significant differences.

\section{Results}

Effect of combination treatment with G-CSF and lithium chloride on hydrocephalus incidence following IVH. To investigate the effect of combination treatment of G-CSF and lithium chloride on hydrocephalus following IVH, rats were divided into five groups (Group 1, IVH control; Group 2, G-CSF treatment; Group 3, lithium chloride treatment; Group 4, combination treatment; and Group 5, sham surgery). G-CSF was used to mobilize endogenous neural stem cells (10). In addition, lithium chloride was observed to have neuroprotective effects by promoting neural stem cell differentiation (11). As shown in Fig. 1A, severe hydrocephalus occurred in the majority of rats in Group 1 after IVH, compared with the rats only subjected to sham surgery (Group 5; $\mathrm{P}<0.001$ ). In addition, the hydrocephalus incidence after IVH in Group 2 and Group 3 rats was significantly decreased compared with that in Group 1 rats (both $\mathrm{P}<0.001$ ). Furthermore, a significant reduced hydrocephalus incidence was observed in Group 4 when compared with that in Groups 2 and $3(\mathrm{P}=0.028 ; \mathrm{P}=0.015)$. Images of brain tissue obtained from rats in the different groups were captured, and are presented in Fig. 1B. The brain of rats in 
A

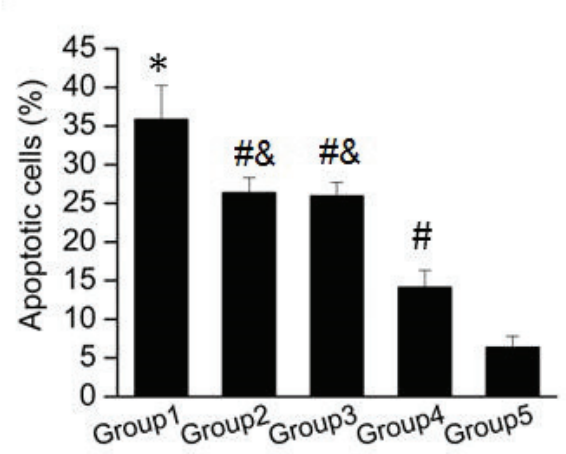

Group 3

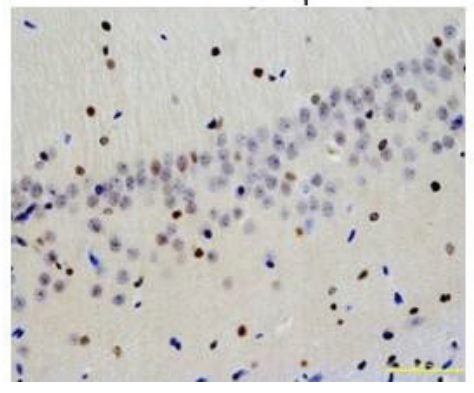

B

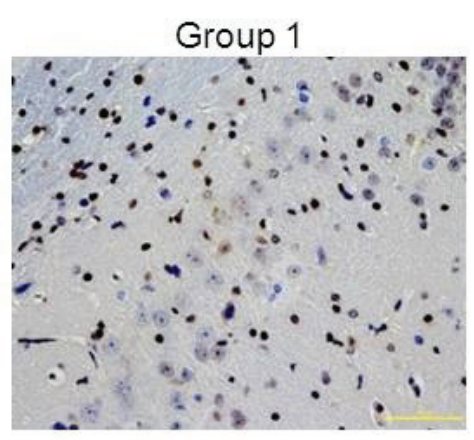

Group 4

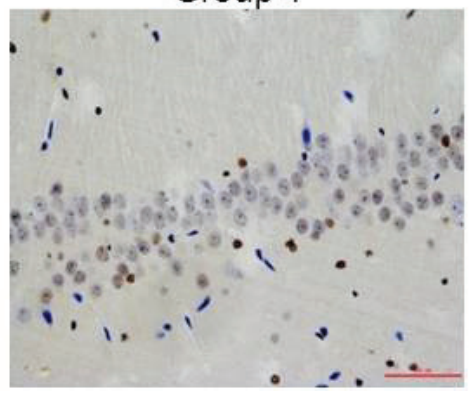

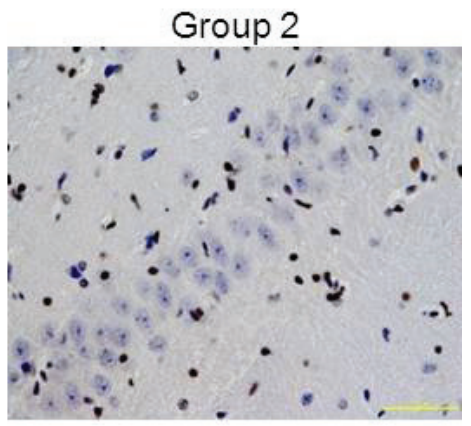

Group 5

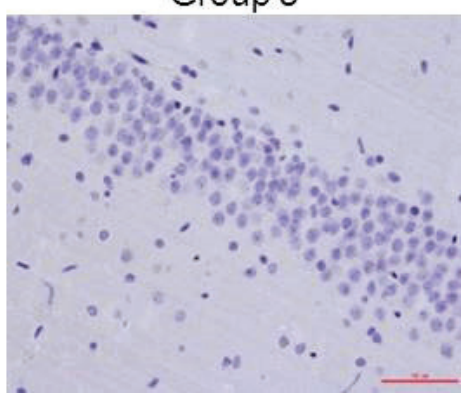

Figure 2. Effect of combination treatment with granulocyte-colony stimulating factor and lithium chloride on nerve cell apoptosis in brain tissue of rats. (A) Percentage of apoptotic nerve cells in brain tissue of the various study groups. The results are presented as the mean \pm standard deviation. "P $<0.05$ vs. Group $5 ;{ }^{\#} \mathrm{P}<0.05$ vs. Group $1 ;{ }^{\circledR} \mathrm{P}<0.05$ vs. Group 4 . (B) Representative immunofluorescence photomicrographs of nerve cell apoptosis observed in the periventricular area of rat brain tissue in the various study groups.

Group 1 appeared to be larger in size when compared with that in other groups. The brains of rats in Groups 2 and 3 were smaller than those in Group 1, however they were still larger in size compared with those in Group 4, which appeared to be closer to the normal brain size in Group 5 (Fig. 1B). These data indicated that combination treatment with G-CSF and lithium chloride was more effective against hydrocephalus after IVH compared with single drug administration, and significantly attenuated the development of hydrocephalus.

Effect of combination treatment with G-CSF and lithium chloride on nerve cell apoptosis in brain tissue. The current study further detected the nerve cell apoptosis in brain tissue samples obtained from the five groups using TUNEL assay. It was observed that the apoptotic cell number in Group 1 was significantly higher than that in Group $5(\mathrm{P}=0.002)$. As shown in Fig. 2A, the amount of apoptotic cells in Groups 2, 3 and 4 were significantly reduced compared with that in Group 1. Furthermore, apoptosis of nerve cells was significantly reduced in Group 4 when compared with that in Groups 2 and 3 (Fig. 2A; both $\mathrm{P}=0.001$ ). Images of the apoptosis assay in brain tissue samples from the five groups are shown in Fig. 2B, further verifying these results. These findings suggested that combination treatment with G-CSF and lithium chloride significantly reduced the nerve cell apoptosis induced by hydrocephalus subsequent to IVH.

Protein expression levels of Bcl-2 and Bax in nerve cells in brain tissue. As Bcl-2 and Bax are known to be involved in cell apoptosis, their protein expression levels were examined in

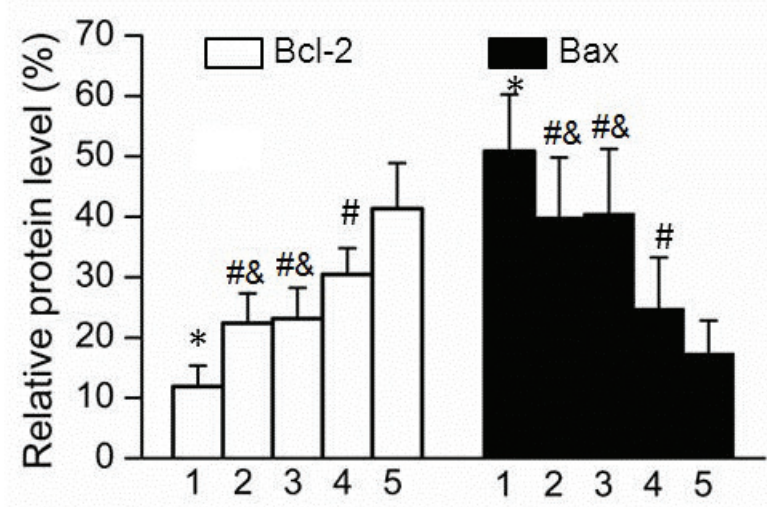

Figure 3. Protein expression levels of Bcl-2 and Bax in nerve cells in brain tissue samples. The results are presented as the mean \pm standard deviation. ${ }^{*} \mathrm{P}<0.05$ vs. Group 5; ${ }^{\#} \mathrm{P}<0.05$ vs. Group $1 ;{ }^{\circledR} \mathrm{P}<0.05$ vs. Group 4 . Bcl-2, B-cell lymphoma 2; Bax, Bcl-2-associated X protein.

nerve cells of brain tissue samples obtained from the various rat groups. As showed in Fig. 3, the protein expression of Bcl-2 in Groups 2 and 3 was significantly higher compared with that in Group 1; however, the expression in Groups 2 and 3 was significantly lower compared with that in Group $4(\mathrm{P}=0.0015 ; \mathrm{P}=0.001)$. By contrast, the expression of Bax was significantly upregulated in Group 1, while a lower protein level was observed in Group 4, when compared with Bax expression in Groups 2 and 3. In addition, the expression levels of $\mathrm{Bcl}-2$ and Bax were significantly decreased or increased in Group 1 compared with that in Group 5, respectively ( $\mathrm{P}=0.003 ; \mathrm{P}=0.0025)$. 
A

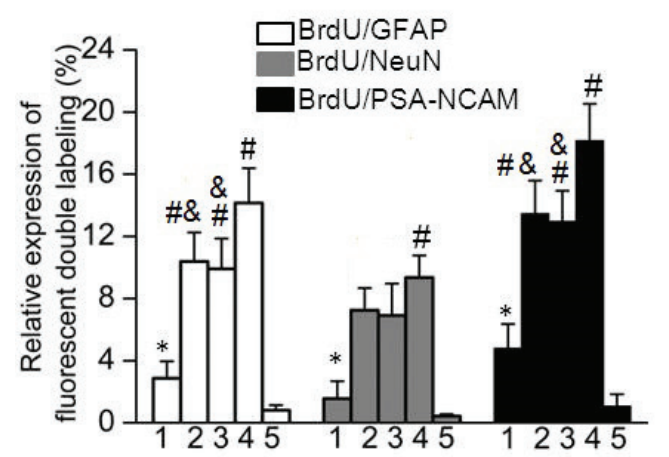

B

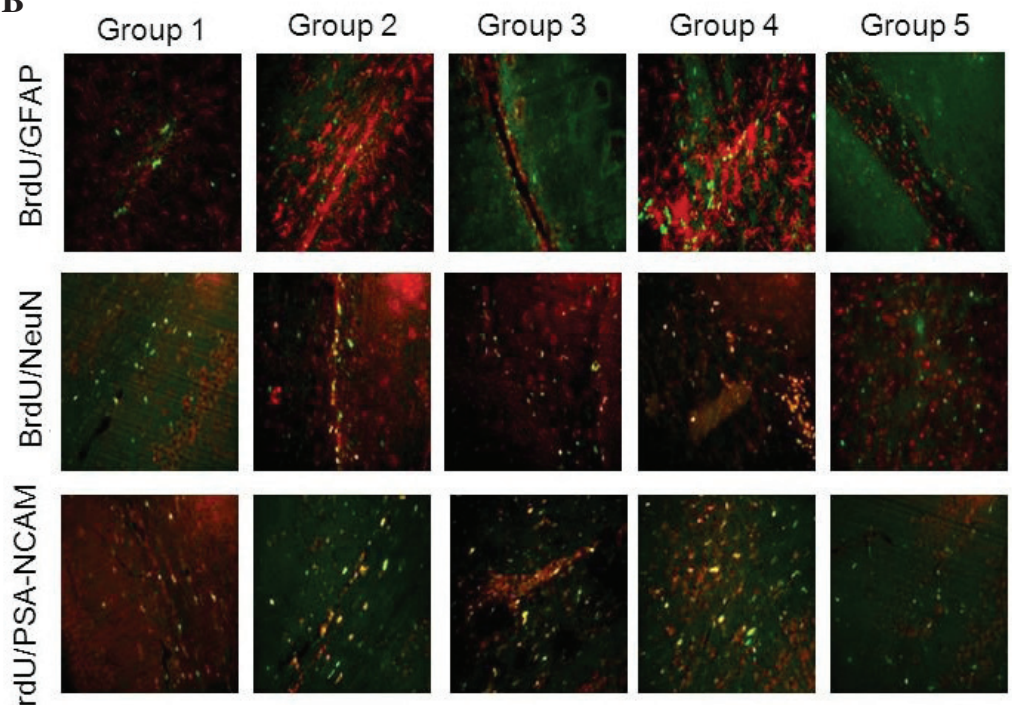

Figure 4. Expression of marker genes as indicators of nerve cell differentiation in brain tissue. (A) Relative expression of fluorescent double labeling of BrdU along with GFAP, NeuN or PSA-NCAM in the five rat groups. The results are presented as the mean \pm standard deviation. ${ }^{*} \mathrm{P}<0.05$ vs. Group 5 ; ${ }^{\prime} \mathrm{P}<0.05$ vs. Group 1; ${ }^{\circledR} \mathrm{P}<0.05$ vs. Group 4. (B) Double-labeled immunofluorescent staining for BrdU/GFAP, BrdU/NeuN and BrdU/PSA-NCAM in brain tissue of rats in the five study groups. BrdU, bromodeoxyuridine; GFAP, glial fibrillary acidic protein; NeuN, neuronal nuclei; PSA-NCAM, polysialylated-neural cell adhesion molecule.

Expression of nerve cell differentiation markers in brain tissue. In order to detect the differentiation of nerve cells in brain tissue samples obtained from the five rat groups, the expression levels of GFAP, NeuN and PSA-NCAM were examined using a double immunofluorescence labeling method with BrdU to evaluate cell proliferation intensity. As shown in Fig. 4, the results demonstrated that the expression levels of BrdU/GFAP, $\mathrm{BrdU} / \mathrm{NeuN}$ and BrdU/PSA-NCAM were significantly upregulated in Group 1 compared with those in Group $5(\mathrm{P}=0.03)$. In addition, the expression levels of BrdU/GFAP, BrdU/NeuN and BrdU/PSA-NCAM in Groups 2 and 3 were significantly increased when compared with that in Group 1 (Fig. 4A). In addition, highest expression levels of BrdU/GFAP, BrdU/NeuN and BrdU/PSA-NCAM were observed in Group 4. The fluorescence distribution images shown in Fig. 4B further verify this differential expression. These data indicated that combination treatment with G-CSF and lithium chloride was more effective at promoting nerve cell differentiation compared with single drug administration.

\section{Discussion}

IVH is the most common severe disease in the area of neurosurgery and results in several complications, including hydrocephalus, high intracranial pressure and the injury of ventricular tissue in the brain (1). Among these, hydrocephalus is the most common complication, which aggravates the damage in brain tissue. It is widely recognized that hydrocephalus subsequent to IVH results from the increased secretion of blood stimulated subarachnoid granules and blood coagulation (22). A series of pathophysiological changes occur during the formation of hydrocephalus, including apoptosis of nerve cells and glial hyperplasia (23). It has been reported that neuronal apoptosis and proliferation of white matter mainly results in irreversible damage of hydrocephalus (5).
Mobilization of bone marrow stem cells is a novel method for cell transplantation, and contributes to the regeneration or repair of nerve cells (24). A specific type of bone marrow stem cells have been shown to positively express $\mathrm{C}-\mathrm{X}$-C chemokine receptor 4 (CXCR4) and possess the function of directional differentiation and migration (25). In addition, CXCR4 was found to be the unique receptor of stromal cell-derived factor-1 (SDF-1) (26). When pathological changes occurred in the central nervous system, SDF-1 was demonstrated to be upregulated and cause the migration of monocytes/macrophages in the blood system into the injury zone, exerting chemotactic effects (27). Reported evidence has indicated that G-CSF may mobilize bone marrow stem cells to stimulate proliferation and differentiation of stem cells (28). G-CSF may exert an anti-apoptotic function by regulating the expression of $\mathrm{Bcl}-2$ and Bax (29). In addition, it is widely known as a growth factor for hematopoietic cells that promotes survival, proliferation and differentiation of cells of the neutrophil lineage (30). Kawabe et al have also suggested that G-CSF exerts neuroprotective effects via the promotion of angiogenesis subsequent to spinal cord injury (31). Furthermore, lithium chloride has been previously reported to reduce the apoptosis of nerve cells by suppressing the activity of glycogen synthase kinase $3 \beta$ and enhancing the absorption of BrdU (15). In the current study, the effect of combination treatment with G-CSF and lithium chloride on hydrocephalus following IVH was investigated. The results demonstrated that single use of G-CSF or lithium chloride only partly relieved the incidence of hydrocephalus following IVH. By contrast, combination treatment with G-CSF and lithium chloride significantly attenuated the development of hydrocephalus following IVH in rats.

The present study further examined the neuronal apoptosis using TUNEL assay in brain tissues. The results showed that neuronal apoptosis was significantly reduced by the combination treatment with G-CSF and lithium chloride. 
Furthermore, the expression of Bcl-2 was upregulated and Bax was downregulated in the combination treatment group. Bcl-2 has been reported to inhibit cell apoptosis, while Bax may stimulate the expression of apoptotic genes (32). These data observed in the present study indicated that combination treatment of G-CSF and lithium chloride was more effective in treating hydrocephalus after IVH compared with treatment with a single agent. In addition, combination treatment exerted a neuroprotective function by reducing the apoptotic cells.

The expression levels of neural stem cell marker NeuN, mature neuron marker PSA-NCAM and mature astrocyte marker GFAP commonly characterize the differentiation of nerve cells (33). The present study observed that the expression levels of BrdU/GFAP, BrdU/NeuN and BrdU/PSA-NCAM in the G-CSF alone or lithium chloride alone treatment groups were significantly increased when compared with those in the IVH control group (Fig. 4A). In addition, the highest levels of BrdU/GFAP, BrdU/NeuN and BrdU/PSA-NCAM were expressed in the combination treatment group. These data indicated that combination treatment with G-CSF and lithium chloride may be able to mobilize bone marrow stromal cells to assemble into the hemorrhage region of brain tissue. Regenerative nerve cells may replace the local necrosis and loss nerve cells. A synaptic linkage between the nerve cells and the surrounding neurons may then be established and the function of neuron cells may be recovered.

In conclusion, the present study demonstrated that the combination of endogenous neural stem cell mobilization using G-CSF and lithium chloride treatment highly reduced the incidence of hydrocephalus following IVH by inhibiting neuronal apoptosis. The findings of the current study provide evidence on the effectiveness of this noninvasive treatment for hydrocephalus occurring subsequent to IVH.

\section{Acknowledgements}

The study was supported by a grant from the Foundation and Advanced Technology of Henan Province (no. 142300410267).

\section{References}

1. Vassilyadi M, Tataryn Z, Shamji MF and Ventureyra EC: Functional outcomes among premature infants with intraventricular hemorrhage. Pediatr Neurosurg 45: 247-255, 2009.

2. Cherian SS, Love S, Silver IA, Porter HJ, Whitelaw AG and Thoresen M: Posthemorrhagic ventricular dilation in the neonate: Development and characterization of a rat model. J Neuropathol Exp Neurol 62: 292-303, 2003.

3. Zacharia BE, Vaughan KA, Hickman ZL, Bruce SS, Carpenter AM, Petersen NH, Deiner S, Badjatia N and Connolly ES Jr: Predictors of long-term shunt-dependent hydrocephalus in patients with intracerebral hemorrhage requiring emergency cerebrospinal fluid diversion. Neurosurg Focus 32: E5, 2012 .

4. Simard PF, Tosun C, Melnichenko L, Ivanova S, Gerzanich V and Simard JM: Inflammation of the choroid plexus and ependymal layer of the ventricle following intraventricular hemorrhage. Transl Stroke Res 2: 227-231, 2011.

5. Chen FM, Wu LA, Zhang M, Zhang R and Sun H: Homing of endogenous stem/progenitor cells for in situ tissue regeneration: Promises, strategies, and translational perspectives. Biomaterials 32: 3189-3209, 2011.

6. Bellenchi GC, Volpicelli F, Piscopo V, Perrone-Capano C and di Porzio U: Adult neural stem cells: An endogenous tool to repair brain injury? J Neurochem 124: 159-167, 2013.
7. Lindvall O, Kokaia Z and Martinez-Serrano A: Stem cell therapy for human neurodegenerative disorders-how to make it work. Nat Med Suppl: S42-S50, 2004.

8. Yanqing Z, Yu-Min L, Jian Q, Bao-Guo X and Chuan-Zhen L: Fibronectin and neuroprotective effect of granulocyte colony-stimulating factor in focal cerebral ischemia. Brain Res 1098: 161-169, 2006.

9. Hartung T: Anti-inflammatory effects of granulocyte colony-stimulating factor. Curr Opin Hematol 5: 221-225, 1998.

10. Schäbitz WR, Kollmar R, Schwaninger M, Juettler E, Bardutzky J, Schölzke MN, Sommer C and Schwab S: Neuroprotective effect of granulocyte colony-stimulating factor after focal cerebral ischemia. Stroke 34: 745-751, 2003.

11. Chuang DM, Chen RW, Chalecka-Franaszek E, Ren M, Hashimoto R, Senatorov V, Kanai H, Hough C, Hiroi T and Leeds P: Neuroprotective effects of lithium in cultured cells and animal models of diseases. Bipolar Disord 4: 129-136, 2002.

12. Chen RW and Chuang DM: Long term lithium treatment suppresses p53 and Bax expression but increases Bcl-2 expression. A prominent role in neuroprotection against excitotoxicity. J Biol Chem 274: 6039-6042, 1999.

13. Chen G, Zeng WZ, Yuan PX, Huang LD, Jiang YM, Zhao ZH and Manji HK: The mood-stabilizing agents lithium and valproate robustly increase the levels of the neuroprotective protein bcl-2 in the CNS. J Neurochem 72: 879-882, 1999.

14. Katoh M: WNT signaling in stem cell biology and regenerative medicine. Curr Drug Targets 9: 565-570, 2008.

15. Hirsch C, Campano LM, Wöhrle S and Hecht A: Canonical Wnt signaling transiently stimulates proliferation and enhances neurogenesis in neonatal neural progenitor cultures. Exp Cell Res 313: 572-587, 2007.

16. Chamnanvanakij S, Margraf LR, Burns D and Perlman JM: Apoptosis and white matter injury in preterm infants. Pediatr Dev Pathol 5: 184-189, 2002.

17. Di Renzo GC, Mignosa M, Gerli S, Burnelli L, Luzi G, Clerici G, Taddei F, Marinelli D, Bragetti P, Mezzetti D, et al: The combined maternal administration of magnesium sulfate and aminophylline reduces intraventricular hemorrhage in very preterm neonates. Am J Obstet Gynecol 192: 433-438, 2005.

18. Chemtob S, Laudignon $\mathrm{N}$ and Aranda JV: Drug therapy in hypoxic-ischemic cerebral insults and intraventricular hemorrhage of the newborn. Clin Perinatol 14: 817-842, 1987.

19. Vose LR, Vinukonda G, Jo S, Miry O, Diamond D, Korumilli R, Arshad A, Zia MT, Hu F, Kayton RJ, et al: Treatment with thyroxine restores myelination and clinical recovery after intraventricular hemorrhage. J Neurosci 33: 17232-17246, 2013.

20. Ahn SY, Chang YS, Sung DK, Sung SI, Yoo HS, Lee JH, Oh WI, Park WS: Mesenchymal stem cells prevent hydrocephalus after severe intraventricular hemorrhage. Stroke 44: 497-504, 2013.

21. Lodhia KR, Shakui P, Keep RF: Hydrocephalus in a rat model of intraventricular hemorrhage. Acta Neurochir Suppl 96: 207-211, 2006

22. Paczkowska E, Dabkowska E, Nowacki P and Machaliński B: Stem cell-based therapy in central nervous system diseases. Neurol Neurochir Pol 43: 550-558, 2009 (In Polish).

23. Rodríguez EM, Guerra MM, Vío K, González C, Ortloff A, Bátiz LF, Rodríguez S, Jara MC, Muñoz RI, Ortega E, et al: A cell junction pathology of neural stem cells leads to abnormal neurogenesis and hydrocephalus. Biol Res 45: 231-242, 2012.

24. Urdzíková L, Jendelová P, Glogarová K, Burian M, Hájek M and Syková E: Transplantation of bone marrow stem cells as well as mobilization by granulocyte-colony stimulating factor promotes recovery after spinal cord injury in rats. J Neurotrauma 23: 1379-1391, 2006.

25. Stumm RK, Rummel J, Junker V, Culmsee C, Pfeiffer M, Krieglstein J, Höllt V and Schulz S: A dual role for the SDF-1/CXCR4 chemokine receptor system in adult brain: isoform-selective regulation of SDF-1 expression modulates CXCR4-dependent neuronal plasticity and cerebral leukocyte recruitment after focal ischemia. J Neurosci 22: 5865-5878, 2002.

26. Rath D, Chatterjee M, Borst O, Müller K, Langer H, Mack AF, Schwab M, Winter S, Gawaz M and Geisler T: Platelet surface expression of stromal cell-derived factor-1 receptors CXCR4 and CXCR7 is associated with clinical outcomes in patients with coronary artery disease. J Thromb Haemost 13: 719-728, 2015. 
27. Blum A, Childs RW, Smith A, Patibandla S, Zalos G, Samsel L, McCoy JP, Calandra G, Csako G and Cannon RO III: Targeted antagonism of CXCR4 mobilizes progenitor cells under investigation for cardiovascular disease. Cytotherapy 11: 1016-1019, 2009.

28. Shyu WC, Lin SZ, Yang HI, Tzeng YS, Pang CY, Yen PS and $\mathrm{Li} \mathrm{H}$ : Functional recovery of stroke rats induced by granulocyte colony-stimulating factor-stimulated stem cells Circulation 110: 1847-1854, 2004.

29. Yata K, Matchett GA, Tsubokawa T, Tang J, Kanamaru K and Zhang JH: Granulocyte-colony stimulating factor inhibits apoptotic neuron loss after neonatal hypoxia-ischemia in rats. Brain Res 1145: 227-238, 2007.

30. Roberts AW: G-CSF: A key regulator of neutrophil production, but that's not all! Growth Factors 23: 33-41, 2005.
31. Kawabe J, Koda M, Hashimoto M, Fujiyoshi T, Furuya T, Endo T, Okawa A and Yamazaki M: Neuroprotective effects of granulocyte colony-stimulating factor and relationship to promotion of angiogenesis after spinal cord injury in rats: Laboratory investigation. J Neurosurg Spine 15: 414-421, 2011.

32. Shen ZJ, Esnault S, Schinzel A, Borner C and Malter JS: The peptidyl-prolyl isomerase Pin1 facilitates cytokine-induced survival of eosinophils by suppressing Bax activation. Nat Immunol 10: 257-265, 2009.

33. Garcia AD, Doan NB, Imura T, Bush TG and Sofroniew MV: GFAP-expressing progenitors are the principal source of constitutive neurogenesis in adult mouse forebrain. Nat Neurosci 7: 1233-1241, 2004 